\title{
Tokyo 2020 Paralimpik Oyunlarına Hazırlanan Sporcularin Anksiyete, Depresyon ve Stres Düzeylerinin İncelenmesi
}

\author{
Fatma Betül YARDIMCI ${ }^{1}$ DD , Bahar ANAFOROĞLU KÜLÜNKOĞLU 2 \\ ${ }^{1}$ Mardin Artuklu Üniversitesi, Fizik Tedavi ve Rehabilitasyon Bölümü, MARDiN \\ ${ }^{2}$ Ankara Yıldııım Beyazıt Üniversitesi, Fizyoterapi ve Rehabilitasyon Bölümü, ANKARA
}

Araştırma Makalesi

DOI:10.53434/gbesbd.987452

\begin{abstract}
Öz
Araștırmanın amacı 2020 Tokyo Paralimpik Oyunlarına hazırlanan engelli sporcuların anksiyete, depresyon, stres seviyelerini belirlemektir. Bu çalışma Paralimpik Oyunlarına hazırlanan 33 erkek ve 23 kadın sporcu olmak üzere toplamda 56 sporcu ile yapılmış ve sporcuların cinsiyet, yaş, eğitim durumu ve spor dalı gibi sosyodemografik özellikleri hakkında bilgiler toplanmıștır. Anksiyete, depresyon, stres seviyelerine ve cinsiyet etkisine ayrıca bunların birbiri ile ilișkisine bakılmıștır. Anksiyete değerlendirmesi için Durumluk-Sürekli Anksiyete Envanteri (State-Trait Anxiety Inventory/STAI), depresyon değerlendirmesi için Epidemiyolojik Araştırmalar Merkezi Depresyon Ölçeği (Center for Epidemiologic Studies Depression Scale/CES-D), stres değerlendirmesi için ise Algılanan Stres Ölçeği (ASÖ-14) kullanılmıştır. Bu çalışmaya katılmıştır. Sporcuların durumluk anksiyete, sürekli anksiyete, depresyon ve stres belirtileri göstermediği bulunmuştur. Cinsiyete göre ise anlamlı bir fark bulunamamısstır $(p>0,05)$. Ayrıca durumluk anksiyete, sürekli anksiyete, depresyon ve stres parametrelerinin birbiri ile anlamlı ilișkisi olduğu görülmüștür. Paralimpik Oyunlar'a hazırlanıyor olmanın sporcuların anksiyete, depresyon ve stres seviyeleri üzerinde olumsuz etkileri gözlemlenmemiștir.
\end{abstract}

Anahtar sözcükler: Engelliler için spor, Anksiyete, Depresyon, Stres

Geliş Tarihi/Received: 26.08.2021 Kabul Tarihi/Accepted: 20.10.2021 Yayın Tarihi/Published: 27.01.2022 Etik Kurul Onayı: Bu araştırma, Ankara Yıldırım Beyazı Üniversitesi Etik Kurulu’nun 08.12.2020 tarih ve 13 sayılı kararı ile etik açıdan uygun bulunmuştur. 


\title{
The Effect of Gender on Anxiety, Depression and Stress Levels of Athletes Preparing for the Tokyo 2020 Paralympic Games
}

\begin{abstract}
The aim of the research is to determine the anxiety, depression and stress levels of disabled athletes preparing for the Paralympic Games and the effect of gender on these parameters. This study was conducted with 56 athletes who were preparing for the Paralympic Games and data was collected about the sociodemographic characteristics of the athletes such as gender, age, educational status and sports branch. Anxiety, depression, stress levels and gender effect also their relationship to each other were analyzed. State-Trait Anxiety Inventory (STAI) for anxiety assessment, Center for Epidemiologic Studies Depression Scale (CES-D) for assessment depression, and Perceived Stress Scale (PSS-14) for stress assessment was used. 33 male and 23 female athletes with an average age of $33.32 \pm 1.2$ participated in this study. It was found that the athletes did not show symptoms of state anxiety, trait anxiety, depression, and stress. There was no significant difference between the scale results of men and women. In addition, it was observed that the state anxiety, trait anxiety, depression and stress parameters were significantly correlated with each other. Preparing for the Paralympic Games have not been observed to have negative effects on the levels of anxiety, depression and stress for athletes.
\end{abstract}

Keywords: Sports for persons with disabilities, Anxiety, Depression, Stress

\section{Giriş}

Engelli sporları, engelliliğin zorlukları ile hayatını devam ettirmek zorunda olan bireylerin rehabilitasyon sporu, hobi olarak yapılan aktiviteler, yarışma sporları gibi her türlü sportif faaliyetlerini kapsamaktadır (Tow, Gober ve Nelson, 2019). Engelli bireylere eşitlik ve temel haklara sahip olma, spor faaliyetlerine katılma imkânı sunan en önemli organizasyonlardan olan Paralimpik Oyunlar, Olimpiyat Oyunları bittikten iki hafta sonra aynı ülke tarafından düzenlenmektedir. Paralimpik Oyunlar ilk kez 1960 Roma Olimpiyatları ardından gerçekleştirilmiștir ve o zamandan beri dört yılda bir yapılmaktadır. Türkiye'nin Paralimpik Oyunlar'a ilk defa katılımı ise 1992 senesinde Barselona'da olmuștur (Türkiye Milli Paralimpik Komitesi, 2021). 2020'de yapılması planlanan Tokyo Paralimpik Oyunları COVID-19 pandemisi nedeniyle 24 Ağustos-5 Eylül 2021 tarihlerine ertelenmiştir.

Engellilerin spora katılımı ve bu konuda desteklenmeleri sosyal yaşama uyum sağlamalarını olumlu yönde etkilemektedir. Spor, engellilik kavramı içerisinde sorun teşkil eden fizyolojik, psikolojik, sosyal ve ekonomik zorlukların aşılmasında, topluma kazanım ve rehabilitasyonda en yararlı yöntemlerden biridir (Tow ve diğerleri, 2019).

Son yüzyılda dünya genelinde psikolojik sağlık sorunların yaygınlaşması ile birlikte bu konularda yapılan çalışmaların sayısı artmış ve spora katılımın anksiyete, depresyon, stres üzerindeki olumlu etkileri saptanmıștır (Eime, Young, Harvey, Charity ve Payne, 2013; Nixdorf, Frank ve Beckmann, 2016; Sabiston ve diğerleri, 2016; Schaal ve diğerleri, 2011; Vella, Swann, Allen, Schweickle ve Magee, 2017). Benzer etkiler engellilere yönelik yapılan çalışmalarda da tespit edilmiştir (Groff, Lundberg ve Zabriskie, 2009; Wipfli, Rethorst ve Landers, 2008). 
Birçok kişi için spora katılım, stresle başa çıkmada etkili bir yöntem olmasının yanı sıra eğlence ve sosyal katılımı temsil etmektedir. Depresyon veya anksiyete bozuklukları gibi psikolojik sorunların başlamasını önlediği de bilinmektedir (Bantjes ve Swartz, 2018; Groff ve diğerleri, 2009; Swartz, Hunt, Bantjes, Hainline ve Reardon, 2019; Wipfli ve diğerleri, 2008). Engelli sporu bütünsel rehabilitasyon ve sosyal entegrasyon için çok değerli bir araçtır. Bantjes ve Swartz (2018) bu koşullarda spora katılımın psikolojik sağlığı geliştirebileceğini öne sürmüşlerdir. Bu açıdan bakıldığında paralimpik sporcu olma deneyimi, bu bireylere engellerinden dolayı karşılaşabilecekleri psikolojik sağlık sorunlarına ve sosyal zorluklara karşı koruyucu bir faktör olarak rol üstlenebilir (Swartz ve diğerleri, 2019).

$\mathrm{Bu}$ çalışmada rekabetin hemen öncesinde yapılan değerlendirmelere göre Paralimpik Oyunlar'a 9 ay gibi uzun bir sürenin olmasından dolayı sporcuların depresyon, anksiyete ve stres seviyelerin düşük olması ve bu parametrelerin birbiri ile ilişkili bulunması beklenilmektedir. Fakat pandemiye bağlı kısıtlamalar ve antrenman süreçlerinin etkilemesi nedeniyle bu olgular olumsuz etkilenebilir. Engelli sporculara ve Paralimpik Oyunlar gibi büyük spor organizasyonlarına hazırlanan sporculara yönelik yapılan çalışmalar kısıtlıdır. Bu çalışmanın amacı 2020 Tokyo Paralimpik Oyunlarına hazırlanan engelli sporcuların anksiyete, depresyon, stres seviyelerini incelemektir.

\section{Yöntem}

\section{Katılimcilar}

Araştırma, 2020 Tokyo Paralimpik Oyunlarına katılmaya hak kazanmış veya kota almak için hazırlanan 11 farklı spor dalındaki [para okçuluk, para atıcılık, para atletizm, para masa tenisi, para halter, tekerlekli sandalye (TS) tenis, para yüzme, paratriatlon, para badminton, TS basketbol, para tekvando] 56 bedensel engelli sporcunun gönüllü katılımı ile yapılmıştır. Türkiye'den 2020 Tokyo Paralimpik Oyunlar'a 87 sporcu katılmıştır. Bu çalışmaya ise 2020 Tokyo Paralimpik Oyunlar'a katılan sporcuların yaklaşık \%41'i (36 sporcu) dâhil edilmiştir.

\section{Verilerin Toplanması}

$\mathrm{Bu}$ araștırma Aralık 2020 tarihinde çevrim içi bir form aracılığıyla web tabanlı bir çalışma olarak uygulanmıştır. Çalışma, Helsinki Deklerasyonu 2008 prensiplerine uygun olarak yapılmıștır ve ilgili üniversitenin Etik Kurulu tarafından onaylanmıştır (Onay tarihi: 08.12.2020, onay karar no: 13).

\section{Veri Toplama Araçları}

Sporcuların cinsiyeti, yaşı, eğitim durumu, medeni hali, spor yaşı, spor dalı gibi sosyodemografik özelliklerine yönelik bilgiler toplanmıştır. Anksiyete değerlendirmesi için Durumluk-Sürekli Anksiyete Envanteri (State-Trait Anxiety Inventory/STAI), depresyon değerlendirmesi için Epidemiyolojik Araştırmalar Merkezi Depresyon Ölçeği (Center for Epidemiologic Studies Depression Scale/CES-D), stres değerlendirmesi için ise Algılanan Stres Ölçeği (ASÖ-14) kullanılmıştır. 
Durumluk-Sürekli Anksiyete Envanteri (State-Trait Anxiety Inventory/STAI): Sporcuların anksiyete düzeylerini tespit edebilmek için STAI kullanılmıştır. Spielberger ve Gorsuch (1970) tarafından geliștirilen envanter, Öner ve Le Compte (1998) tarafindan Türkçe'ye uyarlanmıştır. Bu envanter hem durumluk hem de sürekli anksiyeteyi ayrı ayrı belirleyebilme avantajı sağlayan 20'şer soruluk 2 alt ölçekten oluşur. Durumluk anksiyete belirli zaman ve koşulları göz önünde bulundurarak anksiyeteyi ölçmeyi amaçlarken sürekli anksiyete zaman ve koşullardan bağımsız olarak anksiyeteyi ölçmeyi amaçlar. 2080 arasında puanlar alınabilen bu envanterde yüksek puan yüksek anksiyeteye, düşük puan düşük anksiyeteye işaret eder. STAI'de 36 ve altı puan anksiyetenin olmadığını, 37 42 hafif anksiyeteyi, 43 ve üstü puan ise yüksek anksiyeteyi ifade eder (Sel, 2018).

Epidemiyolojik Araştırmalar Merkezi Depresyon Ölçeği (Center for Epidemiologic Studies Depression Scale/CES-D): Sporcuların depresyon düzeylerini tespit edebilmek için CES-D kullanılmıştır. CES-D, genel popülasyonda depresif belirtilerin tespit edilebilmesi amacıyla geliştirilmiş bir kısa öz bildirim ölçeğidir. Bilimsel çalışmalarda yaygın olarak kullanılmaktadır. 20 maddelik 4'lü likert tip bir ölçektir.0-60 arasında puanlar alınabilen bu ölçekte yüksek puan yüksek depresyona, düşük puan düşük depresyona işaret etmektedir. Amerikan Ulusal Ruh Sağlığı Enstitüsü tarafından geliştirilen bu ölçeği Tatar ve Saltukoglu (2010) Türkçe'ye uyarlamıştır. CES-D ölçeğinde 16 ve üstü puanlar klinik anlamlı depresif belirtilerin göstergesi olarak kabul görmektedir (Tatar ve Saltukoglu, 2010).

Algılanan Stres Ölçeği (ASÖ-14): Sporcuların stres düzeylerini tespit edebilmek için ASÖ-14 kullanılmıştır. Cohen, Kamarck ve Mermelstein (1983) tarafından geliştirilen ASÖ14 Eskin, Harlak, Demirkıran ve Dereboy (2013) tarafından Türkçe'ye uyarlanmıştır. 14 sorudan oluşan ASÖ-14 bazı durumların ne kadar stresli algılandığını ölçmektedir. 5’li Likert tip bir ölçektir. 0-56 arasında puanlar alınabilen bu ölçekte yüksek puan yüksek strese, düşük puan düşük strese işaret etmektedir (Eskin ve diğerleri, 2013). Algılanan stres düzeyinin kesme değeri ise ortalama puan olan 28 olarak kabul edilmektedir (Öztürk, 2020).

\section{Verilerin Analizi}

Sporculardan elde edilen parametrelerin istatistiksel analizi SPSS 21 programında yapılmış ve verilerin normal dağılıma uygunluğu görsel (histogram ve olasılık grafikleri) ve analitik yöntemler (Kolmogorov-Smirnov testi) ile incelenmiştir. Normal dağılıma uyduğu belirlenen değişkenler ortalama \pm standart sapma $(\bar{X} \pm S S)$, sayımla belirlenen değişkenler ise kişi sayısı (n) ve yüzde (\%) değeri ile ifade edilmiştir.

Kadın ve erkeklerin ölçek sonuçlarını karşılaştırmak için bağımsız-t testi; anksiyete, depresyon ve stres arasındaki ilişkinin hesaplanabilmesi için ise Pearson korelasyon testi uygulanmıştır. Anlamlılık değeri için 0,05 kabul edilmiştir. 


\section{Bulgular}

Çalışmanın bu bölümünde yapılan analizler sonunda elde edilen bulgulara yer verilmiştir.

Tablo 1. Katılımcıların demografik ve tanımlayıcı özellikleri

\begin{tabular}{lccc}
\hline & & $\mathbf{N}$ & $\mathbf{\%}$ \\
\hline Cinsiyet & Kadın & 23 & 41,1 \\
& Erkek & 33 & 58,9 \\
\hline Medeni Hal & Evli & 20 & 35,7 \\
& Bekâr & 36 & 64,3 \\
\hline \multirow{2}{*}{ Eğitim Durumu } & İlköğretim & 10 & 17,9 \\
& Lise & 21 & 37,5 \\
& Lisans & 20 & 35,7 \\
& Lisansüstü & 5 & 8,9 \\
\hline
\end{tabular}

$\overline{\mathrm{X}} \pm$ SS= Ortalama \pm Standart Sapma, ÇAA= Çeyrekler Arası Aralık, n(\%)=kişi sayısı(yüzde)

Çalışmaya 11 spor dalından farklı engellilik nedenlerine sahip yaş ortalamaları 33,32 olan $33(\% 58,9)$ erkek ve $23(\% 41,1)$ kadın olmak üzere toplamda 56 sporcu katılmıştır. Katılımcıların demografik ve tanımlayıcı özellikleri Tablo 1'de gösterilmektedir.

Tablo 2. Katılımcıların anksiyete, depresyon ve stres ölçekleri sonuçları

\begin{tabular}{ll}
\hline Ölçekler & $\overline{\mathbf{X}} \pm$ SS \\
\hline STAI_D & $32,77 \pm 8,770$ \\
STAI_S & $36,38 \pm 7,569$ \\
CES_D & $10,82 \pm 7,043$ \\
ASÖ-14 & $18,52 \pm 8,135$ \\
\hline
\end{tabular}

$\overline{\mathrm{X}} \pm$ SS $=$ Ortalama \pm Standart Sapma, STAI_D: Durumluk-Sürekli Anksiyete Envanteri-Durumluk kısmı, STAI_S: Durumluk-Sürekli Anksiyete Envanteri Sürekli kısmı, CES-D= Epidemiyolojik Araștırmalar Merkezi Depresyon Ölçeği, ASÖ-14= Algılanan Stres Ölçeği

Tablo 2'de katılımcıların anksiyete, depresyon ve stres değerleri gösterilmektedir. Yöntem kısmında belirtilen kesme değerleri dikkate alındığında bu çalışmada Paralimpik Oyunlar'a hazırlanan antrenman sürecindeki sporcuların depresyon, stres, durumluk ve sürekli anksiyetelerinin olmadığı görülmektedir.

Tablo 3. Kadın ve erkeklerin ölçek sonuçlarının karşılaştırılması

\begin{tabular}{lllll}
\hline Ölçekler & Kadın $(\overline{\mathbf{X}} \pm$ SS $)$ & Erkek $(\overline{\mathbf{X}} \pm$ SS $)$ & t & p \\
\hline STAI_D & $34,70 \pm 9,063$ & $31,42 \pm 8,437$ & 1,385 & 0,172 \\
STAI_S & $38,22 \pm 6,230$ & $35,09 \pm 8,225$ & 1,589 & 0,130 \\
CES_D & $12,30 \pm 6,898$ & $9,79 \pm 7,061$ & 1,324 & 0,191 \\
ASÖ-14 & $19,04 \pm 7,648$ & $18,15 \pm 8,555$ & 0,401 & 0,690
\end{tabular}

$\overline{\mathrm{X}} \pm$ SS $=$ Ortalama \pm Standart Sapma, STAI_D: Durumluk-Sürekli Anksiyete Envanteri-Durumluk kısmı, STAI_S: Durumluk-Sürekli Anksiyete Envanteri Sürekli kısmı, CES-D= Epidemiyolojik Araștırmalar Merkezi Depresyon Ölçeği, ASÖ-14= Algılanan Stres Ölçeği, $p<0,05$

Tablo 3 incelendiğinde anksiyete, depresyon ve stres seviyeleri açısından kadın ve erkekler arasında anlamlı bir fark olmadığı görülmektedir ( $p>0,05)$. 
Tablo 4. Anksiyete, depresyon ve stresin birbiri ile ilişkisi

\begin{tabular}{llll}
\hline \multirow{2}{*}{ STAI_D } & STAI_S & STAI_D & CES_D \\
\cline { 2 - 4 } CES_D & $\mathrm{r}=0,529$ & & \\
& $\mathrm{p}<0,01$ & & \\
ASÖ-14 & $\mathrm{r}=0,581$ & $\mathrm{r}=0,605$ & \\
& $\mathrm{p}<0,01$ & $\mathrm{p}<0,01$ & $\mathrm{r}=0,605$ \\
& $\mathrm{r}=0,721$ & $\mathrm{r}=0,503$ & $\mathrm{p}<0,01$ \\
\hline
\end{tabular}

r: korelasyon katsayısı, STAI_D: Durumluk-Sürekli Anksiyete Envanteri-Durumluk kısmı, STAI_S: DurumlukSürekli Anksiyete Envanteri Sürekli kısmı, CES-D= Epidemiyolojik Araştırmalar Merkezi Depresyon Ölçeği, ASÖ-14= Algılanan Stres Ölçeği, $p<0,05$

Tablo 4'de anksiyete, depresyon ve stresin birbiri ile ilişkisi verilmiştir. Durumluk anksiyete ile sürekli anksiyete, sürekli anksiyete ile depresyon ve durumluk anksiyete ile stres arasında doğrusal yönde orta şiddetli $(\mathrm{p}<0,01)$; sürekli anksiyete ile stres, durumluk anksiyete ile depresyon ve depresyon ile stres arasında doğrusal yönde kuvvetli bir ilişki $(\mathrm{p}<0,01)$ saptanmıştır.

\section{Tartışma}

Bu çalışma Paralimpik Oyunlar'a hazırlanan engelli sporcuların anksiyete, depresyon, stres seviyelerini belirlemek ve bu parametrelere cinsiyetin etkisini tespit etmek amaciyla yapılmıştır. Çalıșmanın sonuçlarına göre Paralimpik Oyunlar’a hazırlanan sporcuların durumluk anksiyete, sürekli anksiyete, depresyon ve stres belirtileri göstermediği bulunmuştur. Kadın ve erkeklerin ölçek sonuçları arasında ise anlamlı bir fark bulunamamıștır. Ayrıca durumluk anksiyete, sürekli anksiyete, depresyon ve stres parametrelerinin birbiri ile anlamlı ilişkisi olduğu görülmüştür.

Tek başına egzersiz ve fiziksel aktiviteden ziyade organize spor katılımının; anksiyete, depresyon, stres, umutsuzluk duyguları, intihar düşüncesi, intihara teşebbüs, yeme bozuklukları, yasadışı uyuşturucu kullanımı ve tütün ürünleri içme riskinde azalma, benlik saygısının artması, sosyal yeteneklerde iyileşme ve daha iyi bildirilen genel ruh sağlığı ile ilișkili olduğu görülmüștür (Eime ve diğerleri, 2013; Nixdorf ve diğerleri, 2016; Schaal ve diğerleri, 2011). Ayrıca spor yapanlara göre yapmayanlarda psikolojik sağlık sorunları görülme ihtimali \%10-20 daha fazladır (Vella ve diğerleri, 2017).

Junge ve Feddermann-Demont (2016) İsviçre'de üst düzey kadın ve erkek futbolcularda yaptıkları çalışmalarında depresyon oranlarını genel popülasyonla benzer, anksiyete oranlarını ise önemli ölçüde daha düşük bulmuşlardır. Anksiyete ve depresyon arasında da pozitif yönde korelasyon olduğu tespit edilmiştir. Başka bir çalışmada da 10 yıllık süre boyunca doping kontrolünden toplanan idrar örneklerinin analiz edilmesi ile genel popülasyona göre sporcularda daha düşük antidepresan alımı olduğu saptanmıștır (Machnik, Sigmund, Koch, Thevis ve Schänzer, 2009). Schaal ve diğerleri (2011) elit sporcuların yaptıkları sporun doğasına uygun olarak maruz kaldıkları fazla baskıya rağmen sporcularda ruh sağlığı sorunları prevalansının genel popülasyondakinden daha düşük olduğunu bildirmişlerdir. Bahsedilen çalışmalarla benzer olarak bu çalışmada da elit sporcuların anksiyete, depresyon ve stres seviyelerinin düşük düzeyde olduğu 
görülmektedir. Bu durum, elit sporcuların psikolojik dayanıklılık düzeylerinin yüksek olmasından kaynaklanabilir.

Elit sporcuların psikolojik dayanıklılığı her zaman psikopatolojiden tam bir bağıșıklık sağlandığı anlamına gelmemektedir. Bu bireylerde yüksek seviyeye özgü ek baskıların psikolojik sorunların gelişimini kolaylaştırabileceği düșünülebilir. Literatür; sporcuların sosyal, kişisel ve sportif ortamındaki sorunların, psikopatoloji ile ilişkili çok özel stres kaynağı olduğundan da bahseder (Schaal ve diğerleri, 2011). Performans başarısızlığı, spor yaralanmaları, antrenman yoğunluğu, hastalık, mükemmeliyetçilik hatta spor türü gibi birçok faktör sporcuların psikolojik durumlarını etkileyebilir (Lastella, Lovell ve Sargent, 2014; Nixdorf ve diğerleri, 2016; Pluhar ve diğerleri, 2019; Rice ve diğerleri, 2016; Rice ve diğerleri, 2019). Rekabete yaklaştıkça antrenman yükü, yorgunluğun arttığı ve sporcuların anksiyete, depresyon ve stres seviyelerinde artış olduğunu gösteren çalışmalar da bulunmaktadır (Capranica ve diğerleri, 2017; Hamlin, Wilkes, Elliot, Lizamore ve Kathiravel, 2019; Lastella ve diğerleri, 2014; Souza ve diğerleri, 2019). Souza ve diğerleri (2019) yaptıkları bir çalışmada spor dalına bağlı olmaksızın antrenman öncesine göre yarışma öncesinde anksiyete ve stresin önemli ölçüde daha yüksek olduğunu tespit etmişlerdir. Ayrıca elit kadın voleybolcularda hemen antrenman öncesi yapılan değerlendirmelerle psikolojik iyilik hali, depresyon, anksiyete ve stres gibi bulguları araştıran bir çalışma anksiyete ve stresin yüksek olduğunu fakat depresyon olmadığını göstermiştir (Mielgo-Ayuso, Zourdos, Clemente-Suárez, Calleja-González ve Shipherd, 2017). Bu çalışmada değerlendirilen elit sporcularda anksiyete, depresyon ve stres düzeyleri düşük bulunmuştur. Literatürde sıklıkla görüldügü üzere rekabete kalan süre sporcuların psikolojik sağlığını etkilemektedir. Bu araștırmaya katılan sporcular 5 yıllık bir hazırlık sürecinin son 9 ayında değerlendirilmiştir. Bununla birlikte yukarıdaki çalışmalardan farklı olarak bu çalışmanın rekabetin hemen öncesinde yapılmamış olması sporcuları ek bir baskıya maruz bırakmamış ve olumsuz yönde etkilememiş olabilir.

Swartz ve diğerleri (2019) paralimpik sporcuları üst düzey spor performansının zorluklarına ek olarak engellilikleri ile ilgili sosyal sorunların da ruh sağlığı bozuklukları açısından risk altında bırakabileceğini iddia etmişler fakat böyle bir sonuca ulaşamamışlardır. Belinchón-deMiguel, Ruisoto-Palomera ve Clemente-Suárez (2019) omurilik yaralanması olan bir paralimpik kadın sporcuda yaptıkları vaka çalışmasında rekabetçi aktiviteler sırasında sporcunun anksiyete durumu, algılanan psikolojik stres, algılanan efor oranı, algılanan kas ağrısı, vücut sıcaklığı gibi parametrelere bakmıș ve elde edilen sonuçların engelli olmayan sporcularda yapılan çalışmalarla benzer olduğunu görmüşlerdir. Vita ve diğerleri (2016) Charcot-Marie-Tooth hastası paralimpik bir yüzücünün 5 yıllık rekabetçi spor aktivite öncesi ve sonrası değerlendirme sonucunda anksiyetenin azalması, depresyon ve yaşam kalitesinde büyük oranda iyileşme, gelişmiş benlik saygısı gibi olumlu bulgularla karşılaşmışlardır. 12 engelli elit kadın sporcuda yapılan diğer bir çalışmada da depresyon ve anksiyete seviyelerinin düşük değerlere sahip olduğu görülmüştür (Martin, Malone ve Hilyer, 2011). 
2019 yılında ortaya çıkan ve 2021'de hala devam etmekte olan COVID-19 salgını dünyayı etkisi altına almış ve herkesin hayatını farklı ölçülerde etkilemiştir. Küresel bir sağlık tehdidi haline gelen COVID-19 salgınını kontrol altına alabilmek için uygulanan karantina, sosyal izolasyon gibi günlük yaşam alışkanlıkların değişmesi nedeniyle bazı istenmeyen etkiler ortaya çıkmıştır. Özellikle uzun süreli sosyal izolasyon psikolojik durum üzerinde olumsuz bir etkiye sahiptir. Stres semptomları, kafa karıșıklığı ve anksiyete düzeyini artırdığı bildirilmiştir (Brooks ve diğerleri, 2020). Ayrıca insanların hayatındaki bu değişim fiziksel aktivite seviyesinin düşmesine neden olabilir. Maugeri ve diğerleri (2020) COVID-19 pandemisi sırasında fiziksel aktivite düzeylerinin öncesine göre değişimlerini ve pandemi sürecinde fiziksel aktivitenin psikolojik sağlık üzerindeki etkisini araştırmıştır. Çalışmanın sonucunda ise katılımcıların fiziksel aktivite seviyelerinin pandemi öncesine göre COVID-19 pandemisi sırasında büyük ölçüde azaldığı tespit edilmiş ve fiziksel aktivite ile psikolojik sağlık arasında anlamlı pozitif ilişki bulunmuştur. Bu sonuç, pandemi sürecinde fiziksel aktivitenin azalmasının daha kötü psikolojik sağlıkla ilişkili olduğunu göstermiştir. Ayrıca COVID-19 salgını kaynaklı normal şartlarda Tokyo'da 25 Ağustos- 6 Eylül tarihlerinde gerçekleştirilmesi planlanan 2020 Paralimpik Oyunlar'ın 24 Ağustos- 5 Eylül 2021 tarihlerinde yapılmasına karar verilmiştir. Clemente-Suárez, Fuentes-García, de la Vega Marcos ve Martínez Patiño (2020) 2020 Tokyo Olimpiyatları'na 6 ay kala yaptıkları araştırmalarında COVID-19 pandemisinin ve Olimpiyatlar'ın ertelenmesinin olimpik ve paralimpik sporcular tarafindan kişisel ve profesyonel tehdit olarak algılanmadığını göstermişlerdir. Benzer şekilde bu çalışmaya katılan sporcular da COVID-19 pandemisini ve Paralimpik Oyunlar'ın ertelenmesini tehdit olarak algılamamış böylelikle de anksiyete, depresyon ve stres düzeyleri olumsuz etkilenmemiş olabilir.

Genel popülasyonda ve sporcularda psikolojik bir soruna sahip olma ihtimalinin kadınlarda erkeklere göre daha yaygın olduğu birçok çalışma tarafından desteklenmektedir (Machnik ve diğ., 2009; Pluhar ve diğerleri, 2019; Rice ve diğ., 2016; Rice ve diğ., 2019; Schaal ve diğ., 2011; Wolanin, Hong, Marks, Panchoo ve Gross, 2016). Junge ve Feddermann-Demont (2016) elit sporcularda yaptıkları çalışmalarında kadınların depresyon ve anksiyete düzeyinin erkeklere göre daha yüksek olduğu bulmuştur. Bu araştırmada kadın ve erkekler arasında anlamlı bir fark bulunmamıştır. Bunun sebebi yaş, spor yaşı, eğitim durumu, spor dalı, engellilik nedeni gibi bireysel veya toplumsal birçok farklılıktan kaynaklanabilir.

Birçok çalışmada spor ve psikolojik sağlık ilişkisi ile ilgili yeni çalışmalara ihtiyaç olduğu vurgulanmıştır (Eime ve diğerleri, 2013; Mielgo-Ayuso ve diğerleri, 2017; Nixdorf ve diğerleri, 2016; Rice ve diğerleri, 2016; Wolanin ve diğ., 2016). Ayrıca Swartz ve diğerleri (2019) yaptıkları derlemede paralimpik sporcuların ruh sağlı̆̆ semptomları ve bozukluklarını araştıran çok az çalışma olmasını dikkat çekici bulmuşlardır. Elit sporcuların genel psikolojik sağlı̆̆na ilişkin verilerin elde edilmesinin zor olduğu bildirilmiştir. $\mathrm{Bu}$ yüzden araştırmalarda değerlendirilenler genellikle lise veya kolej sporcularıdır (Schaal ve diğerleri, 2011). Bu araştırmanın diğerlerinin aksine elit engelli sporcular ile tasarlanması bakımından literatüre önemli katkı sağladı̆̆ı düşünülmektedir. 


\section{Sonuç ve Öneriler}

Organize spor katılımı engelli bireylerin anksiyete, depresyon ve stres seviyelerini olumlu yönde etkileyebilir. Bu çalışmada Paralimpik Oyunlar'a hazırlanan sporcuların durumluk anksiyete, sürekli anksiyete, depresyon ve stres belirtileri göstermediği ve cinsiyetin bu parametrelere etkisinin olmadığı bulunmuștur. Ayrıca durumluk anksiyete, sürekli anksiyete, depresyon ve stres parametrelerinin birbiri ile anlamlı ilişkisi olduğu görülmüştür. Paralimpik Oyunlar'a hazırlanıyor olma durumunun ve COVID-19 pandemisinin sporcuların anksiyete, depresyon ve stres seviyeleri üzerinde olumsuz etkileri gözlemlenmemiştir.

Çalışmada ölçekler sporculara Paralimpik Oyunlar'a yaklaşık 9 ay kala ve bir kez uygulanmıştır. Zaman içerisinde belli aralıklarla ölçeklerin tekrarlanması rekabete yaklaştıkça sporcuların psikolojik durumlarının değişimini inceleme imkânı sunabilir. Gelecek çalışmalarda bu hususa dikkat edilmelidir.

Elit düzeydeki spor engelli bireylerin psikolojik dayanıklılık seviyelerini artırabilir. Engelli bireylerin spora katılımı teşvik edilmeli ve bu konudaki farkındalığın artırılmasına özen gösterilmelidir. Ayrıca engelli sporcuların düzenli psikolojik takiplerinin yapılması ve ihtiyaç halinde gerekli desteğin verilmesi hem kişisel tedavi gereksiniminin karşılanmasına hem de başarı ve motivasyonunun artmasına katkı sağlayacaktır.

\section{Çıkar Çatışması}

$\mathrm{Bu}$ makalenin yayınlanmasıyla ilgili yazarlar arasında herhangi bir çıkar çatışması bulunmamaktadır.

\section{Yazar Katkıları}

Araştırma Fikri: FBY, BAK; Araștırma Tasarımı: FBY, BAK; Verilerin Analizi: FBY, BAK; Makale Yazımı: FBY, BAK; Eleștirel İnceleme: FBY, BAK

\section{Yazışma Adresi (Corresponding Address):}

Arș. Gör. Fatma Betül YARDIMCI

Mardin Artuklu Üniversitesi, Sağlık Bilimleri Fakültesi, MARDiN

ORCID: 0000-0003-4656-6176

E-posta:fatmabetulyardimci@gmail.com 


\section{Kaynaklar}

1. Bantjes, J. ve Swartz, L. (2018). Social inclusion through para sport: A critical reflection on the current state of play. Physical Medicine and Rehabilitation Clinics of North America, 29(2), 409-16.

2. Belinchón-deMiguel, P., Ruisoto-Palomera, P. ve Clemente-Suárez, V. J. (2019). Psychophysiological stress response of a paralympic athlete during an ultra-endurance event. A case study. Journal of Medical Systems, 43(3), 70.

3. Brooks, S. K., Webster, R. K., Smith, L. E., Woodland, L., Wessely, S., Greenberg, N. ve Rubin, G. J. (2020). The psychological impact of quarantine and how to reduce it: Rapid review of the evidence. The Lancet, 395(10227), 912-20.

4. Capranica, L., Condello, G., Tornello, F., Iona, T., Chiodo, S., Valenzano, A., De Rosas, M., Messina, G., Tessitore, A. ve Cibelli, G. (2017). Salivary alpha-amylase, salivary cortisol, and anxiety during a youth taekwondo championship: An observational study. Medicine, 96(28), e7272.

5. Clemente-Suárez, V. J., Fuentes-García, J. P., de la Vega Marcos, R. ve Martínez Patiño, M. J. (2020). Modulators of the personal and professional threat perception of olympic athletes in the actual COVID-19 Crisis. Frontiers in Psychology, 5(11), 1985.

6. Cohen, S., Kamarck, T. ve Mermelstein, R. (1983). A global measure of perceived stress. Journal of Health and Social Behavior, 24(4), 385-396.

7. Eime, R. M., Young, J. A., Harvey, J. T., Charity, M. J. ve Payne, W. R. (2013). A systematic review of the psychological and social benefits of participation in sport for children and adolescents: Informing development of a conceptual model of health through sport. International Journal of Behavioral Nutrition and Physical Activity, 10(1), 1-21.

8. Eskin, M., Harlak, H., Demirkıran, F. ve Dereboy, C.. (2013). Algılanan stres ölçeğinin Türkçeye uyarlanması: Güvenirlik ve geçerlik analizi. New/Yeni Symposium Journal, 51(3), 132-40.

9. Groff, D. G., Lundberg, N. R. ve Zabriskie, R. B. (2009). Influence of adapted sport on quality of life: Perceptions of athletes with cerebral palsy. Disability and Rehabilitation, 31(4), 318-26.

10. Hamlin, M. J., Wilkes, D., Elliot, C. A., Lizamore, C. A. ve Kathiravel, Y. (2019). Monitoring training loads and perceived stress in young elite university athletes. Frontiers in Physiology, 10, 34 .

11. Junge, A. ve Feddermann-Demont, N. (2016). Prevalence of depression and anxiety in top-level male and female football players. BMJ Open Sport \& Exercise Medicine, 2(1), e000087.

12. Lastella, M., Lovell, G. P. ve Sargent, C. (2014). Athletes' precompetitive sleep behaviour and its relationship with subsequent precompetitive mood and performance. European Journal of Sport Science, 14(sup1), 123-30.

13. Machnik, M., Sigmund, G., Koch, A., Thevis, M. ve Schänzer, W. (2009). Prevalence of antidepressants and biosimilars in elite sport. Drug Testing and Analysis, 1(6), 286-91.

14. Martin, J. J., Malone, L. A. ve Hilyer, J. C. (2011). Personality and mood in women's paralympic basketball champions. Journal of Clinical Sport Psychology, 5(3), 197-210.

15. Maugeri, G., Castrogiovanni, P., Battaglia, G., Pippi, R., D’Agata, V., Palma, A., Di Rosa, M. ve Musumeci, G. (2020). The impact of physical activity on psychological health during Covid-19 pandemic in Italy. Heliyon, 6(6), e04315.

16. Mielgo-Ayuso, J., Zourdos, M. C., Clemente-Suárez, V. J., Calleja-González, J. ve Shipherd, A. M. (2017). Can psychological well-being scales and hormone levels be used to predict acute performance of anaerobic training tasks in elite female volleyball players? Physiology \& Behavior, $180,31-38$. 
17. Nixdorf, I., Frank, R. ve Beckmann, J. (2016). Comparison of athletes' proneness to depressive symptoms in individual and team sports: Research on psychological mediators in junior elite athletes. Frontiers in Psychology, 7, 893.

18. Öner, N. ve Le Compte, A. (1998). Süreksiz durumluk/sürekli kaygı envanteri el kitabı (2. Baskı). İstanbul: Boğaziçi Üniversitesi.

19. Öztürk, A. (2020). Hemșirelik birinci sınıf öğrencilerinin alglladıkları stres ile üniversiteye uyum düzeyleri ve akademik genel not ortalamaları arasındaki ilişkinin incelenmesi. Kıbrıs Türk Psikiyatri ve Psikoloji Dergisi, 2(3), 155-62.

20. Pluhar, E., McCracken, C., Griffith, K. L., Christino, M. A., Sugimoto, D. ve Meehan III, W. P. (2019). Team sport athletes may be less likely to suffer anxiety or depression than individual sport athletes. Journal of Sports Science \& Medicine, 18(3), 490-96.

21. Rice, S. M., Gwyther, K., Santesteban-Echarri, O., Baron, D., Gorczynski, P., Gouttebarge, V., Reardon, C. L., Hitchcock, M. E., Hainline, B. ve Purcell, R. (2019). Determinants of anxiety in elite athletes: A systematic review and meta-analysis. British Journal of Sports Medicine, 53(11), 722-730.

22. Rice, S. M., Purcell, R., De Silva, S., Mawren, D., McGorry, P. D. ve Parker, A. G. (2016). The mental health of elite athletes: A narrative systematic review. Sports Medicine, 46(9), 1333-1353.

23. Sabiston, C. M., Jewett, R., Ashdown-Franks, G., Belanger, M., Brunet, J., O'Loughlin, E. ve O'Loughlin, J. (2016). Number of years of team and individual sport participation during adolescence and depressive symptoms in early adulthood. Journal of Sport and Exercise Psychology, 38(1), 105-10.

24. Schaal, K., Tafflet, M., Nassif, H., Thibault, V., Pichard, C., Alcotte, M., Guillet, T., El Helou, N., Berthelot, G. ve Simon, S. (2011). Psychological balance in high level athletes: Gender-based differences and sport-specific patterns. PloS One, 6(5), e19007.

25. Sel, S. A. (2018). Serebral palsili çocuklarin ebeveynlerinin fizyoterapi ve rehabilitasyon ev programına uyumlarını değerlendirme ölçeğinin geliştirilmesi (Yüksek Lisans tezi). Hacettepe Üniversitesi Sağlık Bilimleri Enstitüsü, Ankara.

26. Souza, R. A., Beltran, O. A. B., Zapata, D. M., Silva, E., Freitas, W. Z., Junior, R. V., da Silva, F. F. ve Higino, W. P. (2019). Heart rate variability, salivary cortisol and competitive state anxiety responses during pre-competition and pre-training moments. Biology of Sport, 36(1), 39-46.

27. Spielberger, C. D. ve Gorsuch, R. L. (1970). STAI manuel of the State-Trait Anxiety Inventoty ("self evaluation questionnaire"). Palo Alto, CA: Consulting Psychologists Press.

28. Swartz, L., Hunt, X., Bantjes, J., Hainline, B. ve Reardon, C. L. (2019). Mental health symptoms and disorders in paralympic athletes: A narrative review. British Journal of Sports Medicine, 53(12), 737-40.

29. Tatar, A. ve Saltukoglu, G. (2010). The adaptation of the CES-Depression Scale into Turkish through the use of confirmatory factor analysis and item response theory and the examination of psychometric characteristics. Klinik Psikofarmakoloji Bülteni-Bulletin of Clinical Psychopharmacology, 20(3), 213-27.

30. Tow, S., Gober, J. ve Nelson, M. R. (2019) Adaptive sports, arts, recreation, and community engagement. Physical Medicine and Rehabilitation Clinics of North America, 31(1), 143-58.

31. Türkiye Milli Paralimpik Komitesi (2021, 2 Haziran). Sık sorulan sorular. Erişim adresi: http://www.tmpk.org.tr/sik-sorulan-sorular/.

32. Vella, S. A., Swann, C., Allen, M. S., Schweickle, M. J. ve Magee, C. A. (2017). Bidirectional associations between sport involvement and mental health in adolescence. Medicine and Science in Sports and Exercise, 49(4), 687-94. 
33. Vita, G., La Foresta, S., Russo, M., Vita, G. L., Messina, S., Lunetta, C. ve Mazzeo, A. (2016). Sport activity in Charcot-Marie-Tooth disease: A case study of a paralympic swimmer. Neuromuscular Disorders, 26(9), 614-618.

34. Wipfli, B. M., Rethorst, C. D. ve Landers, D. M. (2008). The anxiolytic effects of exercise: A metaanalysis of randomized trials and dose-response analysis. Journal of Sport and Exercise Psychology, 30(4), 392-410.

35. Wolanin, A., Hong, E., Marks, D., Panchoo, K. ve Gross, M. (2016). Prevalence of clinically elevated depressive symptoms in college athletes and differences by gender and sport. British Journal of Sports Medicine, 50(3), 167-71. 